\title{
New Perspectives On The Nacre- Organic Interface In Bivalve Shells
}

L.M. OTTER ${ }^{1 *}$, K. EDER ${ }^{2}$, J. GIM ${ }^{3}$, R. HOVDEN ${ }^{3}$, M.R. $\mathrm{KILBURN}^{4}$, L. YANG ${ }^{2}$, J.M. CAIRNEY ${ }^{2}$, D.E. JACOB ${ }^{1}$

${ }^{1}$ Department of Earth and Environmental Sciences, Macquarie University, NSW Australia

${ }^{2}$ Australian Centre for Microscopy and Microanalysis, The University of Sydney, Sydney, NSW 2006, Australia

${ }^{3}$ Department of Materials Science \& Engineering, University of Michigan, Ann Arbor, MI, USA.

${ }^{4}$ Centre for Microscopy Characterisation and Analysis, University of Western Australia, Perth, Australia

* Correspondence to LMO via laura.otter@mq.edu.au

Trace elements and isotopic signatures are continuously recorded in growing shells and are empirically applied to monitor or reconstruct past environmental and climatic conditions. However, the precondition to correctly apply these proxy records is our understanding how trace elements are incorporated into growing biominerals. Although this understanding is still limited, we know today that bivalve shells form via non-classical crystallization pathways involving amorphous calcium carbonate (ACC) nanoparticles that transform to stable polymorphs aragonite or calcite [1]. This concept is not yet fully incorporated into proxy applications and our general understanding of the nano-scale properties of nacre is still limited.

Here, we aim to better understand trace element incorporation and mechanics of bivalve shell nacre at the nano-scale.

We investigate bivalve nacre with NanoSIMS, scanning electron microscopy, and Atom Probe Tomography (APT). At the micron scale, we observe rather homogeneously Srlabelled nacre tablets and a step-like enrichment pattern within one nacre tablet generation, which contrasts to the appearence of Sr-labelled non-nacreous shells [2]. However, at atomic length scales, we find distinct zones of high $\mathrm{Sr}$ enrichment at the mineral-organic interface in the Sr-labelled areas. Similarly, APT shows organic-rich areas embedded in the biomineralized matrix from organic inclusions and the interlamelar membrane [3]. These organic-mineral interfaces play a critical role for the mechanical properties of nacre [4] and are essential for its excellent mechanical resilience.

\section{References:}

[1] De Yoreo et al., 2015, Science. [2] Otter et al., 2019, Biogeosciences. [3] Eder et al., 2019, Geostandards and Geoanalytical Research. [4] Gim et al., 2019, Nature Communications. 